\title{
Teaching Systematic Viewing to Final-Year Medical Students Improves Systematicity but Not Coverage or Detection of Radiologic Abnormalities
}

Citation for published version (APA):

van Geel, K., Kok, E. M., Dijkstra, J., Robben, S. G. F., \& van Merrienboer, J. J. G. (2017). Teaching Systematic Viewing to Final-Year Medical Students Improves Systematicity but Not Coverage or Detection of Radiologic Abnormalities. Journal of the American College of Radiology, 14(2), 235-241. https://doi.org/10.1016/j.jacr.2016.10.001

Document status and date:

Published: 01/02/2017

DOI:

10.1016/j.jacr.2016.10.001

Document Version:

Publisher's PDF, also known as Version of record

Document license:

Taverne

Please check the document version of this publication:

- A submitted manuscript is the version of the article upon submission and before peer-review. There can be important differences between the submitted version and the official published version of record.

People interested in the research are advised to contact the author for the final version of the publication, or visit the DOI to the publisher's website.

- The final author version and the galley proof are versions of the publication after peer review.

- The final published version features the final layout of the paper including the volume, issue and page numbers.

Link to publication

\footnotetext{
General rights rights.

- You may freely distribute the URL identifying the publication in the public portal. please follow below link for the End User Agreement:

www.umlib.nl/taverne-license

Take down policy

If you believe that this document breaches copyright please contact us at:

repository@maastrichtuniversity.nl

providing details and we will investigate your claim.
}

Copyright and moral rights for the publications made accessible in the public portal are retained by the authors and/or other copyright owners and it is a condition of accessing publications that users recognise and abide by the legal requirements associated with these

- Users may download and print one copy of any publication from the public portal for the purpose of private study or research.

- You may not further distribute the material or use it for any profit-making activity or commercial gain

If the publication is distributed under the terms of Article $25 \mathrm{fa}$ of the Dutch Copyright Act, indicated by the "Taverne" license above, 


\title{
Teaching Systematic Viewing to Final-Year Medical Students Improves Systematicity but Not Coverage or Detection of Radiologic Abnormalities
}

\author{
Koos van Geel, MD ${ }^{a}$, Ellen M. Kok, PhD ${ }^{b}$, Joost Dijkstra, PhD ${ }^{b}$, \\ Simon G. F. Robben, MD, PhD , Jeroen J. G. van Merriënboer, PhD ${ }^{b}$
}

\section{Abstract}

Purpose: Systematic viewing of images is widely advocated in radiology; it is expected to lead to complete coverage of images and consequently more detection of abnormalities. Evidence on the efficacy of teaching systematic viewing to students is conflicting. The aim of this study was to investigate the effects of teaching systematic viewing to final-year medical students on systematicity of viewing behavior, coverage of the image, and detection.

Methods: Final-year medical students $(\mathrm{n}=60)$ viewed 10 chest radiographs in a first series before training and another 10 radiographs in a second series after training. Between series, students were taught basic chest radiographic viewing, in either a systematic or a nonsystematic manner. With eye tracking, systematicity (Levenshtein distances), coverage (percentage of image viewed), and detection (sensitivity and specificity) were measured.

Results: In a mixed two-by-two design, significantly higher sensitivity was found after training compared with before training $\left(F_{1,55}=\right.$ $\left.6.68, P=.012, \eta_{\mathrm{p}}{ }^{2}=.11\right)$ but no significant effect for type of training $\left(F_{1,55}=1.24, P=.30\right)$ and no significant interaction effect $\left(F_{1,55}=0.12, P=.73\right)$. Thus, training in systematic viewing was not superior to training in nonsystematic viewing. A significant interaction of training type and time of viewing was found on systematicity $\left(F_{1,49}=20.0, P<.01, \eta_{\mathrm{p}}{ }^{2}=.29\right)$ in favor of the systematic viewing group. No significant interaction was found for coverage $\left(F_{1,49}=0.43, P=.51\right)$ or specificity $\left(F_{1,55}=.124, P=.73\right)$.

Conclusions: Both training types showed similar increases in sensitivity. Therefore, it might be advisable to pay less attention to systematic viewing and more attention to content, such as the radiologic appearances of diseases.

Key Words: Education, perception, systematic viewing, eye movements

J Am Coll Radiol 2017;14:235-241. Copyright (c) 2016 American College of Radiology

\section{INTRODUCTION}

A systematic approach is widely recommended to medical students when they are taught to interpret radiologic abnormalities [1-3]. Such systematic viewing approaches may differ in the order in which anatomic structures should be

\footnotetext{
${ }^{a}$ Department of Radiology, Maastricht University Medical Center, Maastricht, The Netherlands.

${ }^{b}$ Department of Educational Research and Development, School of Health Professions Education, Maastricht University, Maastricht, The Netherlands. Corresponding author and reprints: Koos van Geel, MD, Department of Radiology, Maastricht University Medical Centre, PO Box 5800, 6202 AZ Maastricht, The Netherlands; e-mail: k.vangeel@maastrichtuniversity.nl. The authors have no conflicts of interest related to the material discussed in this article.
}

looked at, but all concur that students need to adhere to one specific order for all images. The principle behind pursuing the same specific order is that students will be less likely to overlook anatomic structures in their viewing process and will therefore be most complete. By completely covering images, medical students are expected to miss less abnormalities. Although it is common practice in radiology departments to teach novices a systematic approach, little research has been performed on its efficacy.

The effects of systematic viewing on detection were investigated by Peterson [4] and Auffermann et al [5]. Peterson found that students who used a complete but nonsystematic search pattern performed significantly 
better than students who used any other search pattern. Peterson's study, however, had only an observational design, and therefore effects of training systematic viewing on detection remained unknown. Furthermore, search patterns and completeness were deduced from think-aloud data rather than from more objective data. Using think-aloud data as a measure of viewing behavior carries the assumption that one could objectively report where one is looking, which is an assumption that does not hold [6]. To objectively measure viewing behavior, the movements of the eyes need to be captured, which can be done by measuring participants' eye movements with eye-tracking apparatus [7].

Auffermann et al [5] investigated the effect of training in systematic viewing on physician assistant trainees evaluating chest radiographs. They found that trainees who participated in the training detected significantly more abnormalities in comparison with the control group. Unfortunately, the control group of this study did not have equal exposure to training in chest radiographic interpretation. Thus, it is unclear whether the increase in detection was the result of the greater educational exposure $[3,8]$ or the result of the instruction to systematically evaluate images. Furthermore, Auffermann et al [5] did not use measures for search patterns or coverage in their methodology, and effects of training on search patterns are therefore unknown.

Thus, to establish the effectiveness of training in systematic viewing, research is required that uses objective (eye-tracking) data to quantify systematic viewing. Furthermore, the effectiveness of training in systematic viewing needs to be established against training in nonsystematic viewing that has equal educational exposure. In this study, we compared a group of final-year medical students who received training in systematic viewing with a similar group who received similar training that did not focus on systematic viewing. Eye movements were measured using eye-tracking methodology. The aim of this study was to answer the following research questions: (1) Does detection of abnormalities increase after training in systematic viewing when medical students view chest $\mathrm{x}$ rays? and (2) Do eye movements change after training in systematic viewing, showing increased systematicity and coverage when medical students view chest $\mathrm{x}$-rays?

\section{METHODS}

\section{Participants}

Final-year medical students $(\mathrm{n}=60 ; 73 \%$ women; mean age, $24.8 \pm 1.54$ years) participated in this experiment. All students were recruited from Maastricht University Medical Centre or affiliated hospitals. Students were recruited via the electronic learning environment of Maastricht University.

All participants had some experience in viewing chest radiographs during their prior clinical rotations but had not received any formal training. Students who had followed an elective chest radiology rotation or who were performing final-year internships in a radiology department were not included. Participants were randomly assigned to one of the two groups; 31 were allotted to the systematic viewing group and 29 to the nonsystematic viewing group. The participants received $\mathrm{a} € 10$ gift voucher as a reward.

\section{Materials}

Apparatus. Eye movements were measured using an SMI RED remote eye tracker (SensoMotoric Instruments, Teltow, Germany). The head movements of participants were not physically restricted. However, to ensure optimal data quality, participants were instructed to avoid head movements as much as possible. The sampling rate was set to $250 \mathrm{~Hz}$, and the eye movements of participants' right eyes were used. The images were shown on a Dell 22-inch liquid crystal display, with a resolution of 1,650 × 1,080 pixels. Before the start of the first (pretraining) and the second (posttraining) series of images, the eye tracker was calibrated using a nine-point calibration. Calibration was repeated until a deviation of less than $1^{\circ}$ of visual angle on both the $\mathrm{x}$ axis and $\mathrm{y}$ axis was acquired. Eye-tracking data from nine participants were excluded from the analysis because of insufficient data quality (ie, the threshold of $1^{\circ}$ of visual angle could not be reached). Data were analyzed using IBM SPSS Statistics version 21 (IBM, Amsterdam, The Netherlands).

Radiologic Images. In this study chest radiographs were used. Chest radiographs not only account for considerable amounts of work in every radiology department [9], but viewing them is also difficult to master [10]. Therefore, using chest radiographs would minimize potential ceiling effects. To ensure the inclusion of images with distinct pathology and distinct normal images, all chest radiographs were individually evaluated by two senior radiologists. Images were included only when the radiologists agreed in their evaluations. All images were stripped of any identifying information. Of the total set of 20 chest radiographs, 17 contained 2 or more abnormalities, and the other 3 were normal. The number of abnormalities was 56 in total: 33 in the pretraining image series and 23 in the posttraining image series (Fig. 1). The abnormalities on the images differed in 


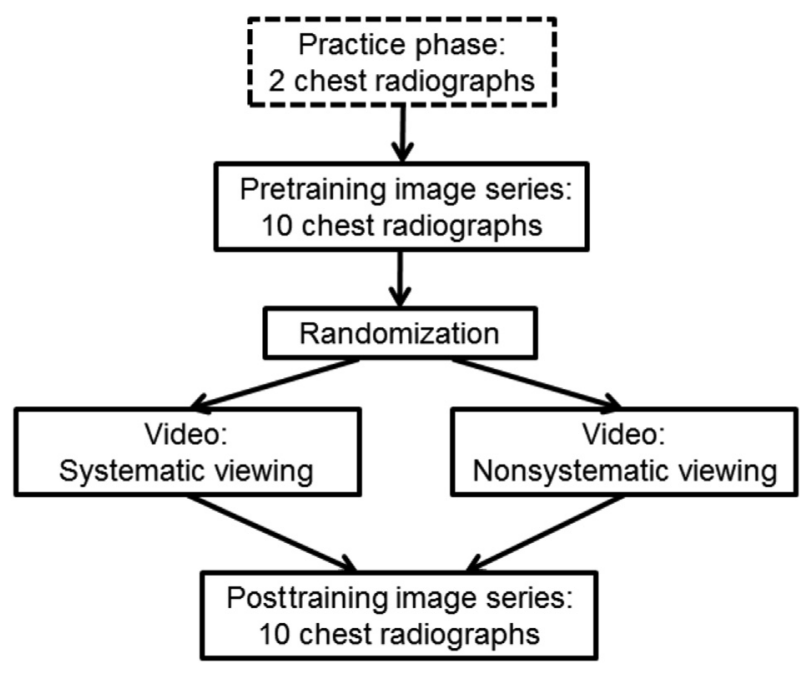

Fig 1. Flow of participants through the experiment.

shape, size, and location and were manifestations of the following diseases: pneumonia, atelectasis, cardiomegaly, pleural effusion, lung tumor, pneumothorax, lung emphysema, and hilar lymphadenopathy.

Training in Systematic and Nonsystematic Viewing. Two instructional videos were used in our experiment to teach participants to use either a systematic viewing approach or a nonsystematic viewing approach. The videos were previously used in an experiment of Kok et al [13]. The training videos differed only with respect to the advocated viewing approach. Participants in both groups hence saw a video approximately $30 \mathrm{~min}$ long in which the basics of chest radiographic interpretation were explained, with the appearances of the previously mentioned cardiopulmonary diseases. Participants saw the video only once and were not allowed to stop, rewind, or fast-forward the video. Moreover, they were not allowed to make notes. In the video for the systematic viewing group, a systematic viewing approach was encouraged. In contrast, the participants in the nonsystematic viewing group were discouraged from using a fixed order during their viewing process. Therefore, they were instructed to view only whatever primarily drew their attention.

\section{Measures}

Detection Measures. Two measures of detection were used, sensitivity and specificity (Table 1). To calculate sensitivity and specificity, participants were asked to click on all abnormalities they saw. Sensitivity was defined as the number of correctly clicked abnormalities divided by the total number of abnormalities of an image series. Sensitivity was calculated per image and then averaged over all images of a series. Specificity was defined as the number of images of an image series for which the participant did not click on any healthy tissue divided by the total number of images of an image series. The detection measures of three participants were not registered because of technical difficulties and were excluded from analysis of sensitivity and specificity.

Systematicity and Coverage Measures. The minimal fixation duration was set to $100 \mathrm{~ms}$. To measure systematicity, Levenshtein distances were calculated [11], which is the most used measure in eye-tracking research for comparing the similarity of the eye movements on two images [7]. Specifically, eye movements on one image can be understood as a string or chain of fixations. By comparing the chain of fixations on one image with the chain of fixations on another image, the similarity of viewing processes per participant can be calculated. To construct such a chain of fixations, we superimposed a seven-byseven grid on each image. We then determined which cells were fixated and in which order. All grid cells were subsequently ranked, on the basis of the time to first fixation. Next, the minimal number of modifications (deletions, insertions, or substitutions) were calculated that were required for the chain of grid fixations of the second image to become the first. Finally, this number was divided by the maximum number of fixated grids, which resulted in the Levenshtein distance. The Levenshtein distances between each pair of images in each series were computed and averaged per participant per image series. Fewer modifications result in a lower Levenshtein distance and indicate higher systematicity.

To measure coverage, a seven-by-seven grid was again superimposed on each image. Coverage was subsequently calculated as the number of grid cells a participant had fixated on at least once, divided by the total number of cells. Coverage was calculated per image and averaged for each of the image series.

\section{Procedure}

The procedure of this experiment is delineated in Figure 1. Before the experiment, participants provided written informed consent. Subsequently, the instructions for the pretraining image series were practiced during a short 
Table 1. Detection measures of the pretraining and posttraining image series in the nonsystematic and systematic viewing groups

\begin{tabular}{|c|c|c|c|c|c|c|c|c|}
\hline \multirow[b]{3}{*}{ Variable } & \multicolumn{4}{|c|}{ Pretraining Image Series } & \multicolumn{4}{|c|}{ Posttraining Image Series } \\
\hline & \multicolumn{2}{|c|}{ Nonsystematic } & \multicolumn{2}{|c|}{ Systematic } & \multicolumn{2}{|c|}{ Nonsystematic } & \multicolumn{2}{|c|}{ Systematic } \\
\hline & $\mathrm{n} \pm \mathrm{SD}$ & $\begin{array}{c}\text { Mean } \\
(\%) \pm \text { SD }\end{array}$ & $\mathrm{n} \pm \mathrm{SD}$ & $\begin{array}{c}\text { Mean } \\
{[\%] \pm \text { SD }}\end{array}$ & $\mathrm{n} \pm \mathrm{SD}$ & $\begin{array}{c}\text { Mean } \\
(\%) \pm S D\end{array}$ & $\mathrm{n} \pm \mathrm{SD}$ & $\begin{array}{c}\text { Mean } \\
\text { (\%) } \pm \text { SD }\end{array}$ \\
\hline Sensitivity* & $14.1 \pm 4.1$ & $42.6 \pm 12.5$ & $14.8 \pm 4.2$ & $44.8 \pm 12.7$ & $10.8 \pm 2.2$ & $46.8 \pm 9.61$ & $11.6 \pm 2.9$ & $50.3 \pm 12.7$ \\
\hline Specificity $^{\dagger}$ & $5.3 \pm 1.9$ & $53.0 \pm 18.9$ & $4.6 \pm 2.0$ & $45.9 \pm 19.7$ & $6.0 \pm 1.8$ & $60.3 \pm 17.6$ & $4.5 \pm 2.1$ & $44.7 \pm 21.1$ \\
\hline
\end{tabular}

*Numbers ( $n \pm$ SD) of sensitivity represent average found abnormalities per image series for both groups.

${ }^{\dagger}$ Numbers ( $n \pm$ SD) of specificity represent average correctly identified images per image series for both groups.

practice phase with two chest radiographs. For the pretraining image series, participants were asked to view the radiographs as they would during their clinical rotations. When they finished viewing a radiograph, participants pressed the space bar, whereupon a new screen was opened, in which they could type in text to describe their findings. Furthermore, the first image of this series was used to validate the eye-tracker calibration. The sensitivity, specificity, and eye movements of the pretraining image series were recorded.

After completion of the pretraining image series, participants saw their respective training video. During the videos, the eye movements of the participants were not recorded. After their training, participants viewed the radiographs of the posttraining image series, and the sensitivity, specificity, and eye movements were again recorded. Contrary to the pretraining image series, they were not asked to view as they would during their clinical rotations but to follow the instructions of their respective systematic or nonsystematic training. There were no time restrictions during image series. Each participant performed the experiment in an individual session. Only after completion of the whole experiment could the diagnoses of the images be provided at the request of the participant.

\section{Analyses}

Two-by-two analyses of variance with the factors type of training (systematic viewing versus nonsystematic viewing) and time of viewing images (posttraining versus pretraining) were used to identify intergroup differences on systematicity, coverage, and detection measures. Each analysis of variance tested three effects: two main effects of each separate factor and one interaction effect between the two factors. The main effect of type of training is an estimation of the overall difference between the nonsystematic and the systematic training group. The main effect of time of viewing is an estimation of the change from pretraining to posttraining. The interaction effect is an estimation of the relation between the change over time and the difference between the two groups: for example, does the change over time of sensitivity significantly differ between the systematic and the nonsystematic viewing group? Therefore, the research questions can be answered by looking at the interaction effect. The $\eta_{\mathrm{p}}{ }^{2}$ statistic was calculated to measure effect size, with .01 indicating a small effect, .06 indicating a moderate effect, and .14 indicating a large effect [12].

\section{Ethical Review}

Ethical approval was received from the ethical review board of Dutch Association for Medical Education (NVMO-ERB), file number 334.

\section{RESULTS}

Does Detection of Abnormalities Increase After Training in Systematic Viewing When Final-Year Medical Students View Radiologic Images?

The detection measures of the pretraining and posttraining image series can be found in Table 1 and are visualized in Figure 2. No significant interaction effect between type of training and time of viewing of the posttraining images series compared with the pretraining image series was found on sensitivity $\left(F_{1,55}=0.12, P=.73, \eta_{\mathrm{p}}{ }^{2}=.002\right)$. However, there was a main effect of time of viewing, showing significantly higher sensitivity in the posttraining image series compared with the pretraining image series for both groups $\left(F_{1,55}=6.68, P=.012, \eta_{\mathrm{p}}^{2}=.11\right)$. Furthermore, there was no significant main effect of training $\left(F_{1,55}=1.24, P=.30, \eta_{\mathrm{p}}{ }^{2}=.022\right)$. Thus, training in systematic viewing did not yield more improvement on sensitivity than training in nonsystematic viewing.

No significant interaction between type of training and time of viewing was found on specificity 

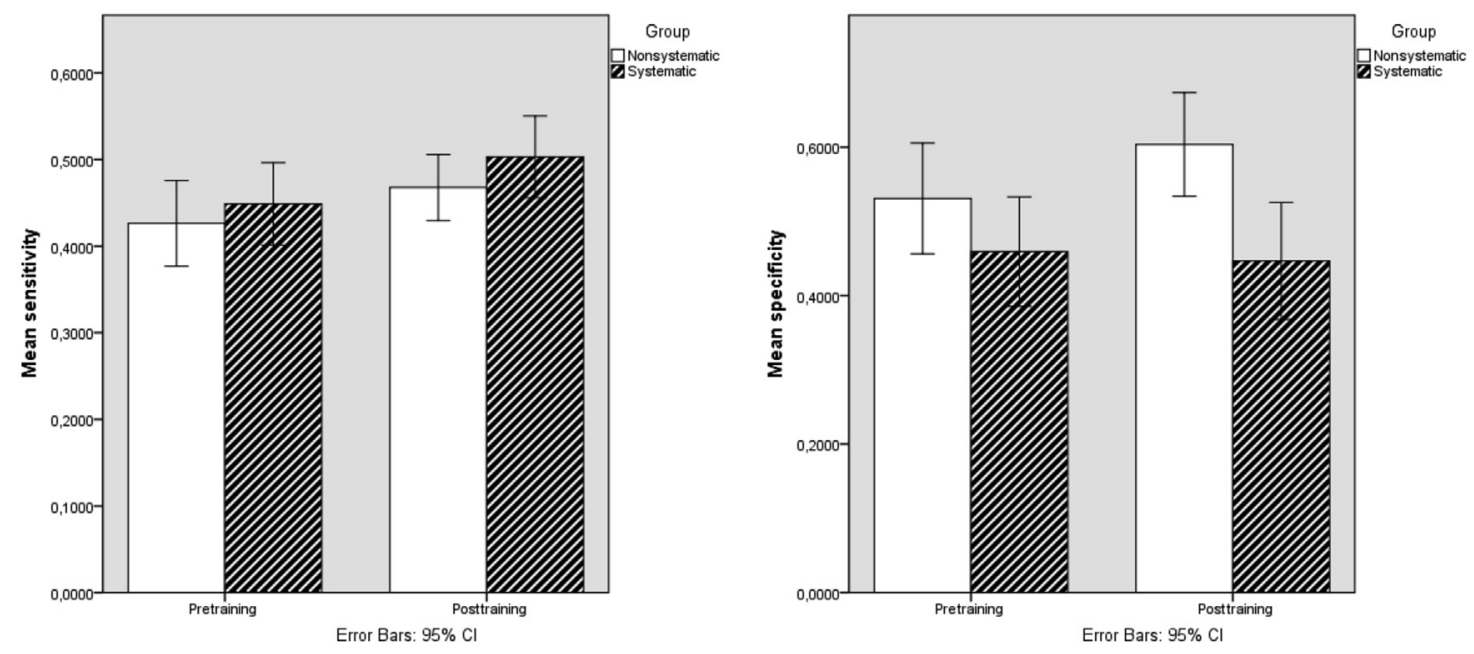

Fig 2. Pretraining and posttraining detection measures of the nonsystematic and systematic group.

$\left(F_{1,55}=0.124, P=.73, \eta_{\mathrm{p}}^{2}=.002\right)$. Thus, training in systematic viewing did not yield more improvement on specificity than training in nonsystematic viewing. There was no main effect of time of viewing on specificity $\left(F_{1,55}=0.847, P=.36, \eta_{\mathrm{p}}^{2}=.015\right)$. There was, however, a significant effect of type of training $\left(F_{1,55}=8.23\right.$, $\left.P<.01, \eta_{\mathrm{p}}{ }^{2}=.13\right)$ : participants in the nonsystematic group had higher overall specificity compared with those in the systematic group.

\section{Do Eye Movements Change After Training in Systematic Viewing, Showing Increased Coverage and Systematicity When Final-Year Medical Students View Radiologic Images?}

The coverage and systematicity of both groups of the pretraining image series and the posttraining image series can be found in Table 2 and are further visualized in Figure 3. Most important, there was a significant interaction between type of training and time of viewing on systematicity $\left(F_{1,49}=20.0, P<.01, \eta_{\mathrm{p}}{ }^{2}=.29\right)$, indicating that the systematic group became significantly more systematic compared with the nonsystematic group after the training in systematic viewing. Furthermore, there was a main effect of time of viewing on systematicity $\left(F_{1,49}=11.3, P<.01, \eta_{\mathrm{p}}{ }^{2}=.19\right)$, and there was a significant effect of training on systematicity: participants in the systematic group were significantly more systematic than participants in the nonsystematic group $\left(F_{1,49}=12.5, P<.01, \eta_{\mathrm{p}}^{2}=.20\right)$.

The interaction effect of type of training with time of viewing on coverage was not significant $\left(F_{1,49}=\right.$ $\left.0.43, P=.51, \eta_{\mathrm{p}}{ }^{2}=.01\right)$. Thus, the increase in coverage of the systematic group did not significantly differ from the increase in the nonsystematic group. There was a main effect of time of viewing on coverage $\left(F_{1,49}=14.8, P<.01, \eta_{\mathrm{p}}{ }^{2}=.23\right)$, indicating that coverage increased after the training in both groups. There was also a main effect of type of training on coverage $\left(F_{1,49}=6.80, P=.012, \eta_{\mathrm{p}}{ }^{2}=.12\right)$, showing higher coverage for the systematic viewing group than the nonsystematic viewing group.

\section{DISCUSSION}

We investigated the effects of training in systematic viewing on detection, systematicity, and coverage of radiologic abnormalities among final-year medical students. With regard to the first research question, whether

Table 2. Eye movement measures of the nonsystematic and systematic viewing groups during the first and second image series

\begin{tabular}{|c|c|c|c|c|c|c|c|c|}
\hline \multirow[b]{3}{*}{ Variable } & \multicolumn{4}{|c|}{ Pretraining Image Series } & \multicolumn{4}{|c|}{ Posttraining Image Series } \\
\hline & \multicolumn{2}{|c|}{ Nonsystematic } & \multicolumn{2}{|c|}{ Systematic } & \multicolumn{2}{|c|}{ Nonsystematic } & \multicolumn{2}{|c|}{ Systematic } \\
\hline & Mean & $\mathrm{SD}$ & Mean & SD & Mean & SD & Mean & SD \\
\hline Coverage & $65.7 \%$ & $8.00 \%$ & $70.6 \%$ & $10.0 \%$ & $71.6 \%$ & $12.1 \%$ & $77.8 \%$ & $9.16 \%$ \\
\hline Levenshtein distance & .89 & .03 & .89 & .022 & .89 & .015 & .85 & .032 \\
\hline
\end{tabular}

Note: A lower Levenshtein distance indicates higher systematicity. 

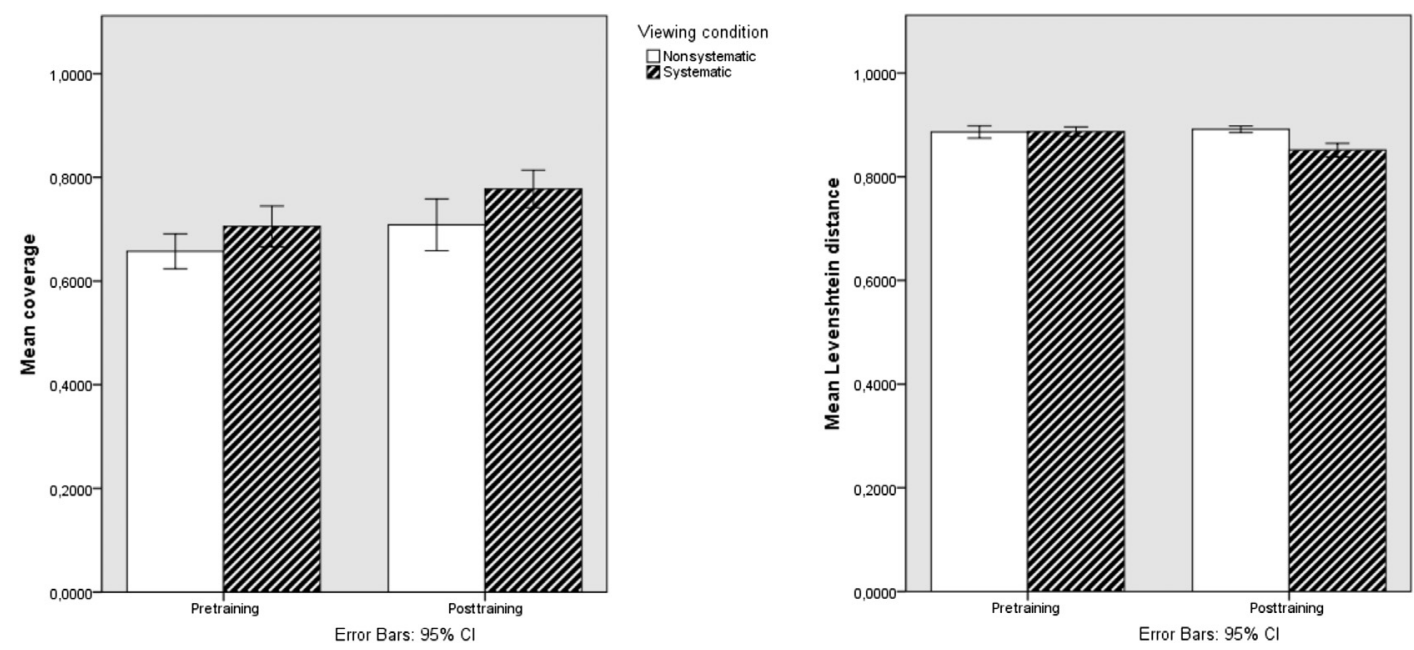

Fig 3. Pretraining and posttraining eye movement measures of the nonsystematic and systematic group.

detection increases after training in systematic viewing training, sensitivity in both groups increased significantly, and to the same degree, after their respective training. The types of training in this research differed only with respect to how the radiologic content was taught; training in systematic viewing did not prove superior to training in nonsystematic viewing. Therefore, the findings of this research indicate that when teaching radiology to medical students, training should primarily emphasize on radiologic content, such as radiologic manifestations of diseases, rather than on training search patterns.

With regard to the second research question, whether eye movements change after training in systematic viewing, showing increased systematicity and coverage, a significant interaction effect on systematicity was found, indicating that the systematic viewing group significantly increased their systematicity, whereas the systematicity of the nonsystematic group remained stable. We therefore conclude that both groups were able to adapt their viewing behavior on the basis of their respective instructions and thus followed the provided instructions. Moreover, no significant interaction effect on coverage was found, although both groups significantly increased in coverage after their training. This indicates that to increase coverage, training in systematic viewing is also not favorable to training in nonsystematic viewing, in which students were instructed to look at whatever drew their attention.

Our finding that training in systematic viewing does not increase detection may seem contradictory to Auffermann et al's [5] findings. In Auffermann et al's study, however, participants of the control group had less exposure to chest radiographs, and the systematic viewing group was trained more extensively than the control group. Training and exposure to radiographs is a strong factor in learning radiology [10]. Indeed, in a setup similar to ours but with third-year medical students, no difference in detection was found between training in systematic viewing and training in nonsystematic viewing [13].

Because training in systematic viewing was not found to be superior to increase detection, the role of training in systematic viewing in radiology education should be further examined. In education, however, not only efficacy but also the preferences of students should be considered. Students prefer their radiology education to include systematic viewing approaches, as it might give them guidance [14]: many students find it initially difficult to start viewing radiographs, as they do not know yet where to begin. Indeed, students consider such approaches valuable when applied [5].

Because students prefer the guidance of systematic viewing in their education, further research should focus on ways to optimize such guidance. Instead of using a lecture or an instructional video to teach students how to use a systematic approach, methods that provide more support should be considered. Checklists have the potential to be such a supportive method. Checklists are essentially lists of criteria, organized in a systematic fashion [15,16], to ensure that all steps in a complex procedure, such as viewing a radiologic image, are considered. Because checklists have already proved their worth for learning in other medical specialties, such as surgery [17], further research on the effectiveness of checklists for learning radiology is therefore implicated [16]. 


\section{Limitations}

The present study had some limitations. First, no clinical information of the images was provided during the experiment. Because clinical information potentially influences viewing behavior [18] and we were interested in the role of training in systematic viewing on viewing behavior, this particular factor was controlled for in this experiment. However, to further unravel the effects of training in systematic viewing on learning to view radiographs, future research should focus on the combined effects of clinical information and training in systematic viewing on detection and viewing behavior.

Second, the training used in this experiment consisted of instructional videos of approximately $30 \mathrm{~min}$ long, which may be too limited to extensively train participants. Although short-term effects were found in this study, effects of training viewing behavior in the long term have not been investigated so far. Further research should therefore investigate the long-term effects of training in systematic viewing on detection and viewing behavior.

\section{TAKE-HOME POINTS}

- Teaching radiology to final-year medical students increases the detection of abnormalities on chest radiographs.

- Systematic viewing was not found to be superior for the detection of abnormalities.

- Radiology education should emphasize the contents of images, such as the radiologic appearances of diseases and variants of normal.

\section{REFERENCES}

1. Daffner RH. Clinical radiology: the essentials. Philadelphia: Lippincott, Williams \& Wilkins; 2007.
2. Eastman GW, Wald C, Crossin J. Getting started in clinical radiology: from image to diagnosis. New York: Thieme; 2006.

3. Kourdioukova EV, Valcke M, Derese A, Verstraete KL. Analysis of radiology education in undergraduate medical doctors training in Europe. Eur J Radiol 2011;78:309-18.

4. Peterson C. Factors associated with success or failure in radiological interpretation: diagnostic thinking approaches. Med Educ 1999;33: 251-9.

5. Auffermann WF, Little BP, Tridandapani S. Teaching search patterns to medical trainees in an educational laboratory to improve perception of pulmonary nodules. J Med Imaging (Bellingham) 2015;3:011006.

6. Ericsson KA, Simon HA. Protocol analysis: verbal reports as data. Cambridge, Massachusetts: MIT Press; 1993.

7. Holmqvist K, Nyström M, Andersson R, Dewhurst R, Jarodzka H, Weijer J. Eye tracking: a comprehensive guide to methods and measures. New York: Oxford University Press; 2011.

8. Sendra-Portero F, Torales-Chaparro OE, Ruiz-Gomez MJ. Medical students' skills in image interpretation before and after training: a comparison between 3rd-year and 6th-year students from two different medical curricula. Eur J Radiol 2012;81:3931-5.

9. Levin DC, Rao VM, Parker L, Frangos AJ. Analysis of radiologists' imaging workload trends by place of service. J Am Coll Radiol 2013;10:760-3.

10. Manning DJ, Ethell SC, Donovan T, Crawford T. How do radiologists do it? The influence of experience and training on searching for chest nodules. Radiography 2006;12:134-42.

11. Levenshtein VI. Binary codes capable of correcting deletions, insertions and reversals. Soviet Physics Doklady 1966;10:707-10.

12. Field AP. Discovering statistics using SPSS. Thousand Oaks, California: Sage; 2009.

13. Kok E, Jarodzka H, Bruin AB, Bin Amir H, Robben SGF, Merriënboer JJ. Systematic viewing in radiology: seeing more, missing less? Adv Health Sci Educ Theory Pract 2016;21:189-205.

14. Subramaniam RM, Beckley V, Chan M, Chou T, Scally P. Radiology curriculum topics for medical students: students' perspectives. Acad Radiol 2006;13:880-4.

15. Hales BM, Pronovost PJ. The checklist—a tool for error management and performance improvement. J Crit Care 2006;21:231-5.

16. Marcovici P, Blume-Marcovici A. Intuition versus rational thinking: psychological challenges in radiology and a potential solution. J Am Coll Radiol 2013;10:25-9.

17. Haynes AB, Weiser TG, Berry WR, et al. A surgical safety checklist to reduce morbidity and mortality in a global population. N Engl J Med 2009;360:491-9.

18. Kundel HL, Wright DJ. The influence of prior knowledge on visual search strategies during the viewing of chest radiographs. Radiology $1969 ; 93: 315-20$. 